\title{
Insights into Endophytic Bacterial Diversity of Rice Grown Across the Different Agro-ecological Regions of West Bengal, India
}

\author{
Pranamita Kunda \\ Jadavpur University Faculty of Science \\ Abhishek Mukherjee \\ Indian Statistical Institute \\ Kumar Kumar Dhal ( $\nabla$ paltuk.dhal@jadavpuruniversity.in ) \\ Jadavpur University Faculty of Science https://orcid.org/0000-0001-5790-3268
}

\section{Research Article}

Keywords: Agro-ecological zones, amplicon metagenomics, rice root endophytes and 16S rRNA gene sequencing

Posted Date: August 16th, 2021

DOI: https://doi.org/10.21203/rs.3.rs-504039/v1

License: (c) (1) This work is licensed under a Creative Commons Attribution 4.0 International License. Read Full License 


\section{Abstract}

Endophytes have recently garnered importance worldwide and multiple studies are being conducted to understand their important role and mechanism of interaction inside plants. But before we indulge in their functions it is necessary to dig into the microbiome. This will help to get a complete picture of the microbes intrinsic to their host and understand changes in community composition with respect to their habitats. To fulfil this requirement in our study we have attempted to dissect the endophytic diversity in roots of rice plant grown across the various agro-ecological zones of West Bengal by undergoing amplicon analysis of their 16S rRNA gene. We found that the agro-ecological zones can be divided into two groups: nutrient dense (GAZ, NHZ and TTAZ) and nutrient low groups (CSZ, RLZ and VAZ). Few genera (Aeromonas, Sulfurospirillum, Uliginosibacterium, etc.) are present in samples cultivated in all the zones representing the core microbiome of rice in West Bengal while some other genera like Lactococcus, Dickeya, Azonexus, Pectobacterium, etc. are unique to specific zone. It can be concluded that understanding which particular endophytes cohabit with the internal plant environment can play an important role in endophyte-based stress management strategy.

\section{Introduction:}

Rice is the most important staple food for more than half the world's population. India is one of the leading producers and consumer of rice and the state of West Bengal is one of the highest producers of rice in India (Kunda et al., 2018). However, rice production is impeded by several abiotic and biotic factors. Therefore, to improve the productivity of crops, farmers apply a wide range of chemical fertilizers and pesticides which in excess leave eco-toxic residues in the soil and in longer term, decrease crop productivity (Kumar Bag, 2011). These toxic chemicals are also responsible for global warming and groundwater pollution (Mashiane et al., 2017). To combat these problems, recent developments are being made to use potential microorganisms to manage biotic and abiotic stress and improve plant growth for a healthier environment (Edwards et al., 2015; Mashiane et al., 2017). Microbiomes associated with plants roots are known to play a significant role in hastening plant growth, development and can alter plant health as well as their stress tolerance abilities (Lareen et al., 2016). These microbes can reside either in the rhizopsheric soil in close association with the roots or can remain inside the plant as endophytes (Olanrewaju et al., 2017). Symbiotic bacterial endophytes of rice provide multiple benefits to their host. They adapt different mechanisms to protect plants from various stressful conditions like drought, salinity, pathogen attack (Khare et al., 2018; Mukhtar et al., 2019). They do so by increasing carbon and nitrogen metabolism, enhancing photosynthetic activity as well as detoxifying enzymes activities, reducing damage caused by reactive oxygen species, producing osmotic regulators, ACC deaminase enzyme, various phytohormones and also by inducing systemic resistance in plants (Edwards et al., 2015; Taulé et al., 2021; Y. Zhang et al., 2019). Root exudates from plants also trigger up-regulation of genes in bacteria that are involved in transporters, efflux pumps and enzymes. It has been observed that plant- associated bacteria tend to have larger genome than non-plant associated species (Pini et al., 2011) and these genes are mainly related to transport, regulation, sugar metabolism, nodulation, etc. (Checcucci et al., 2017). At present, little information is available for plant-microbes interaction at molecular level since it is not a typical "gene-for-gene" interaction (Nautiyal et al., 2013). Therefore, studying plant-microbe relationship can be highly advantageous in establishing a sustainable plant root microbiome system.

For better understanding of the mechanisms of interaction between plants and microbes it is imperative to identify the plant endophytic microbiomes (Kunda et al., 2018). Hence, studying endophytic diversity becomes the foremost requisite in plant-microbe interaction. Since bacteria has established a close bilateral interaction with its surrounding environment, study of bacterial diversity plays a crucial role in understanding biodiversity-ecosystem functioning (Kang et al., 2006) and various plant-related process (Kumar et al., 2018). This knowledge will also provide information about the core microbiome of a particular region that can help plants sustain challenging environments. Recently, culture independent 16S rRNA gene based sequencing are being performed to gain knowledge of endophytic bacterial composition in different economically important crop plants like maize, potato, tomato, tobacco and soybean (Lei et al., 2019). These studies have helped us to gather some knowledge about bacterial diversity, community and composition inside the plants and its relation with soil microbiome (Edwards et al., 2015). However, all these interpretations/studies are at a nascent stage and more in depth knowledge are required to answer all the queries (Pinski et al., 2019).

Regarding study of rice endophytic bacteria a lot of work has been done on isolation and characterization of endophytic bacterial isolates and their potential role in promoting plant growth under diverse conditions (Hardoim et al., 2011; Kang et al., 2006; Moronta-Barrios et al., 2018). Studies on total microbial diversity using metagenomic methods have provided knowledge on rice endosphere composition and function (Sessitsch et al., 2012) as well as their dynamic changes. But in India, work on bacterial diversity of rice are either based on diversity of rice seed endophytes (Chaudhry et al., 2017; Verma et al., 2001) or from rice plants grown under aerobic condition (Vishwakarma \& Dubey, 2020), or from particular varieties (Banik et al., 2017.; Sengupta et al., 2017) or bacteria isolated from rice root rhizosphere (Arjun \& Harikrishnan, 2011). These works are mainly one dimensional focussing on a single site with limited sample numbers. Even though endophytic microbes of many plants are being studied but our knowledge on endophytic bacterial ecology of rice is limited. Ahn et al. (2016), also confirmed that the abundance and diversity of microbes in rice fields that affect crop growth are not well documented (Ahn et al., 2016). Therefore, the main aim of our study was to provide information regarding the rice endophytic community across different agro-ecological zones in West Bengal, i.e. a representation of the rice bacterial endophytes in the state. Since agro-ecological zones are diverse, this study will provide a baseline on various endophytes that colonize rice plants grown throughout West Bengal.

West Bengal being one of the highest producers of rice its endophytic community is not explored properly yet (Kunda et al., 2018). There are no reports available so far as per our knowledge on the endophytic bacterial community of rice across the different regions of this state. As our sampling covers different ecological zones, we hypothesized that different endophytic communities will colonize rice plants due to the influence of the environmental variables that characterize these ecological regions. In West Bengal, which can be broadly divided into six agro-ecological zones, rice is cultivated in almost all the zones (Kumar Bag, 2011). But the regions comprising the old and new alluvial soil i.e. Gangetic Alluvial zone and Vindhyan Alluvial zone are the main rice producing areas (Ghosh et al., 2005). The western part of West Bengal, comprising the Red and Laterite zone are made up of undulating lands with isolated peaks and flat plains which in general are drought prone regions whereas the extreme southern part has Coastal Saline zone which is frequently washed by brackish water from the Bay of Bengal (Kumar Bag, 2011). Rice production is affected in these regions due to various abiotic stress conditions like salinity and drought. 
Hence, the need arises for search of potential endophytes that comprise the core microbiomes of different regions so that formulating endophyte-based stress management becomes easy. Keeping this in mind the primary objectives of our study are: i) to characterize the microbial community among the six different agro-ecological regions based on 16S rRNA gene sequencing; ii) to see if there is any differences in the community composition among the zones, i.e. characterizing unique and core microbiomes of the different zones; iii) to see if there is any relation in microbial community composition among the zones or if variation in microbial community is dependent on any specific environmental parameter. Since soil type has a great impact on bacterial composition we would study how bacterial diversity changes with different zones and which environmental parameters are responsible for the changes in endophytic bacterial composition.

\section{Material And Methods:}

\section{Site description and sample collection:}

Rice (Oryza sativa) plants were sampled at the vegetative stage in the year 2016-2017 during Spring (March) and Autumn (September) from the six different agro ecological regions of West Bengal (Fig 1), namely, Coastal saline zone (CSZ), Gangetic alluvial zone (GAZ), Northern Hill zone (NHZ), Red and Laterite zone (RLZ), Terai-Teesta alluvial zone (TTAZ) and Vindhyan alluvial zone (VAZ). From each zone, three rice fields were sampled and three plants were randomly collected from each field along with their respective rhizospheric soil. The rice varieties that were primarily cultivated in those particular sampling sites were sampled. For example, the local name of the cultivar from CSZ is Lal Miniket, GAZ is Swarnamasuri, NHZ is Kalo Nunia, RLZ is MTU1010, TTAZ is Khitish and VAZ is Tualipanji. The plants were dug out carefully to prevent any damage to the roots. Immediately after collection the samples were placed in autoclaved plastic bags (Himedia), kept on ice and brought back to the laboratory for further processing within 24 hours. Rice roots of plants from the same field were pooled together for DNA extraction.

\section{Analysis of soil physicochemical properties:}

The physical and chemical properties including pH, electrical conductivity (EC), total organic carbon (TOC), available nitrogen ( $\mathrm{N}$ ), available phosphorus ( $\mathrm{P}$ ) and available potassium $(\mathrm{K})$ of the soil samples were also measured. $\mathrm{pH}$ and electrical conductivity of the soil samples was determined by (Jackson, $\mathrm{M}$ L. (1967)) using Systronic (India) pH meter model No. 335 and Systronic (India) conductivity - TDS meter 307 respectively. The organic carbon (OC) of soil was estimated by titration following the method of (Walkley \& Black, 1934). The quantity of available phosphorous of soils was determined by following Olsen's method by spectrophotometric analysis using spectrophotometer (Systronics - 117, India) (Olsen, 1954). Available potassium was determined from the neutral normal ammonium acetate $\left(\mathrm{NH}_{4} \mathrm{OAc}\right.$ ) extracts (soil: $\mathrm{NH}_{4} \mathrm{OAc}$, ratio of 1:10) by Flame photometer (Jackson, $\mathrm{M} \mathrm{L}$. (1967)).

\section{Metagenome extraction and amplicon metagenomic sequencing:}

Surface sterilization of roots was done following the protocol by Sessitch et al. (2012), with few modifications which has been established in our previous paper (Kunda et al., 2018). Briefly, soil particles were removed by washing and then roots were separated from the shoot portion, rinsed with sterile distilled water followed by $0.1 \%$ tween 20 solutions and surface sterilized. The surface sterilized roots were then frozen with liquid nitrogen and grounded to a fine powder using sterile mortar and pestle. DNA was extracted in duplicates using Power Plant Pro DNA isolation kit (Mo Bio) following manufacturer's instructions. The replicated DNA samples were pooled together and sequenced. Sequencing was performed on Illumina Miseq platform in a $2 \times 300$ bp pairedend run. PCR amplification of the hypervariable V3-V4 regions of bacterial 16S rRNA gene was done with universal primers 341F and 806R. The amplicon libraries were prepared using Nextera XT Index kit (Illuminainc.) and Nextera XT DNA Library Prep Kit (Part \# 15044223 Rev. B). The amplicon libraries were purified by 1 X AMpure XP beads and quantified using Qubit fluorometer. The raw paired-end primer trimmed sequences were provided by Eurofins, Germany.

\section{Sequence data processing:}

For all the samples the raw FastQ dataset (R1- forward read \& R2- reverse read) were processed following (Hassenrück et al., 2016) and (Dhal et al., 2020) protocol. Sequences were trimmed based on minimum quality score of 15 and window size of 4 bases using trimmomatic v0.32. The trimmed sequences were then merged using PEAR v0.9.5 and OTU (operational taxonomic unit) clustering was performed using swarm v2.0 with default parameters. The quality filtered OTUs were taxonomically assigned using SINA (SILVA Incremental Aligner; v1.2.11; Silva reference database release 132) with a minimum similarity alignment of 0.9. OTUs assigned as mitochondrial /and chloroplast were excluded from further studies using well standardized $R$ scripts (Hassenrück et al., 2016).

\section{Statistical analysis:}

A principal component analysis (PCA) was performed on the environmental parameters to evaluate the effects of these parameters on sampling sites. Manova (multivariate analysis of anova) was done to check differences in the parameters among the sampling sites.

Alpha diversity indices were calculated to evaluate species richness and evenness of bacterial community composition in all the samples. The a-Diversity indices were measured using repeated random sub-sampling of the amplicon sequence datasets. Species richness and evenness was represented by OTU number, Chao 1 estimator, Shannon diversity index, inverse Simpson diversity index, percentage of absolute (occurs only once in the complete data set) and relative singletons (occurs only once in one sample in the complete data set) as well as absolute doubletons (occurs only twice in the complete data set). Differences in bacterial communities as indicated by alpha diversity among the agro-ecological zones were tested with a paired Wilcoxon test. P - Values of pair wise comparisons based on Wilcoxon tests were adjusted using FDR correction.

Beta diversity as indicated by the differences in composition of the bacterial communities among the samples were visualized by cluster analysis and nonmetric multidimensional scaling (NMDS) using a Bray-Curtis dissimilarity matrix calculated separately from the OTU data of the different agro-ecological zone 
samples. In case of cluster analysis Bray-Curtis dissimilarities were calculated based on relative sequence abundances of OTUs. Analysis of similarity (ANOSIM) was tested to assess the separation of bacterial communities among the sampling sites based on similar environmental parameters. Redundancy analysis (RDA) assessed the ability of environmental parameters to explain the variation in bacterial community composition. Prior to RDA, the data set was reduced by removing OTUs with low sample coverage and rare OTUs i.e. OTUs that did not occur in at least 2 replicates in each location per sample type and those that were not present in less than $10 \%$ of the samples were removed from the dataset. Although this removal affected $83 \%$ of the 0TUs we confirmed that this process did not affect the trends in beta diversity as is given by mantel test. Furthermore, the sequence counts were clr-transformed with the aldex.clr function of the R package ALDEx2, using the median of 128 Monte Carlo Dirichlet instances. Prior to significance testing parameters were excluded using forward model selection and best fitting RDA models were selected based on maximum adjusted $\mathrm{R}^{2}$ and minimum AIC value (Akaike Information Criterion, which estimates the quality of statistical models based on given datasets). Variance inflation factors of the explanatory variables in the best-fitting models were below 10. The differentially abundant OTUs among the zones were reflected in Dotplot prior to this test. The unique and common genera among the agro-ecological zones were identified by using Venn diagram (Bardou et al., 2014). Those genera that had abundance less than $0.5 \%$ were not included in the Venn diagram.

All statistical analysis and figure visualization was performed in R software package, version 3.6.2 using the R core distribution (R Core Team, 2019) along with additional packages vegan (Oksanen,H. et al., 2016) and ALDEx2 (Fernandes et al., 2014).

\section{Nucleotide accession number:}

The raw sequence data reported in this paper were submitted to NCBI with Bioproject accession numbers for 16S rRNA gene sequences as following: PRJNA471586, PRJNA471587, PRJNA471590, PRJNA471599, PRJNA471617 and PRJNA394071.

\section{Results:}

\section{Environmental parameters:}

Studying the environmental parameters of the different agro-ecological zones revealed that all the six parameters tested, i.e., $\mathrm{pH}$, electroconductivity (EC), total organic carbon (TOC), available phosphorus (P), potassium (K) and nitrogen (N), differs significantly among the zones (Supplementary Fig. 1) as revealed by Manova test (Manova, Pillai $=4.16, \mathrm{df}=(5,12)$, p-value $=0.0001)$. PCA analysis showed that the first two axes, PC1 and PC2, could explain $72.9 \%$ variation in the samples based on environmental parameters. $\mathrm{pH}, \mathrm{EC}$, available $\mathrm{P}, \mathrm{K}$ and $\mathrm{N}$ were the major contributors to $\mathrm{PC} 1$ which accounted for $50.52 \%$ of the total variation. Similarly, $22.44 \%$ variation in PC2 is mainly attributed to TOC (Fig. 2). Based on the PCA patterns the sampling sites that clustered together belonged to a particular agro-ecological zone. The distinct separation of CSZ from the rest of the regions may be attributed to the fact that this zone recorded highest EC among the sampling sites. CSZ was also separated from rest of the zones based on all the aforementioned environmental parameters with emphasis on EC and N. It recorded the highest EC value of $5.61 \mathrm{dS} / \mathrm{m}$ and the lowest $\mathrm{N}$ value of $21.99 \mathrm{ppm}$ in average. Samples from NHZ and TTAZ (both belonging to the northern part of West Bengal) were discreet from the other zones with respect to their TOC and $\mathrm{N}$ content. These two zones recorded highest values of TOC (1.45\% and 1.65\%) and $\mathrm{N}$ (70ppm and 73ppm) respectively. Likewise, the separation of VAZ was mainly driven by $\mathrm{pH}$ as it has recorded the highest pH among all the sampling sites which is 6.9 (close to neutral) on average. In rest of the zones pH values are in the range of 5 , indicating slightly acidic soil. PCA pattern corroborated the separation of sampling sites was based on the studied environmental parameters.

\section{Bacterial Diversity And Taxonomic Composition:}

A total of $115,73,768$ paired end reads were generated by amplification of V3-V4 region of the 16S rRNA gene with average reads of 321,494 (ranging from $181,085$ to 507,482$)$ per sample. After trimming and merging the paired end reads high quality reads were clustered using $>97 \%$ sequence identity which generated a total of 386,785 OTUs. To avoid rare biosphere and PCR artifacts low abundance OTUs as well as those affiliated to chloroplast and mitochondria were removed which resulted in taxonomically classified denoised unique sequences clustered into 21,608 OTUs (Supplementary table 1). The OTUs were again pruned and finally 3491 OTUs were obtained. Mantel test was performed using Bray-Curtis dissimilarities method (Mantel test, $R=0.99, p=0.001)$ and Jaccard dissimilarity method (Mantel test, $R=0.98, p=0.001$ ) which proved that the trends in beta diversity was not altered after data pruning.

The Alpha diversity, i.e. within sample diversity, was indicated as rarefied average OTUs per sites. nOTUs from all the samples ranged from 408 to 3197 where GAZ recorded the highest number and CSZ the lowest. This significant difference in species richness among the different agro-ecological zones was given by Kruskal-Wallis test $\left(X^{2}=12.9, d f=5, p\right.$-value $\left.=0.02\right)$. CSZ was significantly different from GAZ ( $p$-value $\left.=0.001\right), R L Z(p$-value $=0.02)$ and TTAZ $(p$-value $=0.04)$, whereas GAZ differed significantly from NHZ ( $p$-value $=0.01$ ). Species richness and evenness as indicated by abundance based coverage estimator (invS) and Shannon index also followed the same pattern which was highest for GAZ (21.6 and 4.35) and lowest for CSZ (1.14 and 0.41) respectively (Supplementary Fig. 2).

At phylum level, the bacterial communities of the agro-ecological zones could be explained with only 4 abundant phyla affiliated to Firmicutes (22-98\% among all samples), Proteobacteria (1-57\%), Epsilonbactereota (0.14-34\%) and Bacteroidetes (0.03-20\%) which represented almost $97 \%$ of the total sequences. Zones like GAZ, NHZ and TTAZ showed predominance of Proteobacteria (32-57\%) followed by Firmicutes (16-50\%), whereas in the other three zones, viz., RLZ, VAZ and CSZ Firmicutes (42-98\%) was the dominant phylum succeeded by Proteobacteria (1-39\%). The other phyla that represented GAZ are Bacteroidetes and Spirochaetes. Rest of the zones except CSZ were governed by Epsilonbactereota and Bacteroidetes whereas almost all the samples of CSZ are represented by Firmicutes. The phylum, Nitrospirae, was present among samples from all the zones except in CSZ. Relative abundances of phyla such as Actinobacteria, Bacteroidetes, Epsilonbactereota, Patescibacteria, Planctomycetes and Proteobacteria were significantly different across the different zones (Anova, p-value< 0.01) (Supplementary Fig. 3). 
The same pattern was also accompanied at the class level. The top 7 dominant classes obtained in this study represented almost about $95 \%$ of the sequences. GAZ, NHZ and TTAZ showed abundance of Gammaproteobacteria succeeded by Clostridia which were totally opposite as in case of the other three zones. The next abundant class for GAZ was Bacteroidia whereas for NHZ, TTAZ and RLZ it is Campylobacteria. VAZ on the other hand showed abundance of Negativicutes. Noteworthy to mention, Alphaproteobacteria mostly dominated zones like NHZ and Bacilli were abundant only in GAZ whereas in all other zones it did not contribute significantly in community composition. For CSZ 95\% of the sequences were occupied by Clostridia. The class Planctomycetes was found in only 3 zones, NHZ, TTAZ and RLZ. Based on relative abundance, classes such as Actinobacteria, Bacilli, Bacteroidia, Campylobacteria, Clostridia, Gammaproteobacteria, Negativicutes and Planctomycetes differ significantly across the agro-ecological zones (Anova, p-value< 0.01) (Fig. 3).

In lower taxonomy level, the top 14 families explained the maximum variation in bacterial community composition among the different zones and they almost accounted for $80 \%$ of the sequences. Except for TTAZ in all the other zones, viz. GAZ, NHZ, RLZ, VAZ and CSZ family Clostridiaceae 1 was dominant. In case of TTAZ, Sulfurospirillaceae was the predominant family. The next abundant family was different for all the zones. For GAZ its Enterobacteriaceae, both NHZ and VAZ showed abundance of Rhodocyclaceae, RLZ was dominated by Sulfurospirillaceae and TTAZ by Clostridiaceae 1. Other families which showed dominance among the zones are Aeromonadaceae among GAZ and NHZ, Burkholderiaceae among NHZ and RLZ and Veillonellaceae in VAZ (Supplementary Fig. 4).

The unique and core genera distributed along the agro-ecological zones were identified by Venn diagram. There are 15 genera which are common in all the sampling sites; among them Clostridium sensu stricto 1 was the most dominant with an abundance of about $33.7 \%$ (average of all the samples) and genus Enterobacteriaceae Incertae sedis was the least abundant with average of $0.5 \%$. However, two zones have few genera distinctive to them. GAZ and TTAZ have 3 unique genera with abundance not less than $0.5 \%$. Moreover, the abundance of these isolated genera in all the samples was not greater $1.1 \%$, indicating they represent the rare microbiome (Supplementary Fig. 5).

\section{Variation In Microbial Community Composition:}

In OTU level, there is a significant variation in bacterial community composition among all the zones as given by ANOSIM (ANOSIM, R $=0.549, \mathrm{p}=0.001)$. The OTUs that are responsible for the variations in bacterial community among the six agro-ecological zones were identified by dot plot (Fig. 4). In total, there are 17 differentially abundant OTUs among all sampling sites. These OTUs were mainly affiliated to Gammaproteobacteria (8 OTUs), Negativicutes (4 OTUs), Clostridia (2 OTUs), Alphaproteobacteria (1 OTU), Campylobacteria (1 OTU), and Spirochaetia (1 OTU). Among class Clostridia, OTU 1 belonging to Clostridium sensu stricto was abundant in all the sampling sites whereas OTU 11 also affiliated with Clostridium sensu stricto was found to be abundant in RLZ, TTAZ and VAZ only and was not present in the other 3 sites. Genera such as Uliginosibacterium (OTU3) and Acidaminococcaceae Incertae sedis (OTU7), of the classes Gammaproteobacteria and Negativicutes respectively was also found to be enriched in all the zones. The genus, Veillonellaceae Incertae sedis (OTU 6 and OTU14), was abundant among NHZ, RLZ, TTAZ and also VAZ but was absent in CSZ. It was also observed that genera like Enterobacter (OTU5) and Burkholderiaceae Incertae sedis (OTU68) both belonging to the class Gammaproteobacteria were found to be dominant only in 3 zones, viz. TTAZ, RLZ and VAZ and show decreasing trend in the other 3 zones. Another genus, Comamonas (OTU70), of the class Gammaproteobacteria, is predominant only in VAZ. Except, GAZ and CSZ, the genera Aquitalea (OTU22) and Aeromonas (OTU4 and OTU10) belonging to class Gammaproteobacteria and genus Sulfurospirillum (OTU2) belonging to class Campylobacteria, are present distinctly in all the zones. The class Alphaproteobacteria represented by the genus, Pleomorphomonas (OTU30), is enriched among the sampling sites of NHZ and in some sites of VAZ. In a similar fashion, the genus Treponema 2 (OTU51) belonging to class Spirochaetia was abundant is sites of GAZ and RLZ only.

To represent the original position of communities in multidimensional space sampling sites were placed in an ordination space as well as their associated environmental parameters on NMDS plot (Fig. 5). Based on Bray-Curtis dissimilarities the six agro-ecological zones tend to cluster apart from each other. CSZ was separated from the rest of the zones based on EC; NHZ was separated due to TOC and separation of RLZ, VAZ were mainly associated with N and P. Envfit that indicates which environmental parameters are strongly correlated with the data shows that patterns in bacterial community composition has strong correlation with EC, K, N and TOC. To assess the role of environmental factors in explaining the variation in bacterial community composition among the agroecological zones redundancy analysis (RDA) was performed (Table 1). RDA revealed that P and TOC could explain about $19 \%$ variation in the bacterial communities. Although the explanatory power is not considerably high but still it is statistically significant. P alone (pure effects) contributed significantly to explain $12 \%$ variation in bacterial communities (AIC - 180.8) while the effect of TOC along with $\mathrm{P}$ (total effects) was significant in explaining the variation (AIC - 180.38). Other parameters like $\mathrm{pH}, \mathrm{EC}, \mathrm{K}$ and $\mathrm{N}$ were not selected in the best fitting model apparently because they did not contribute essentially in explaining the variation. Together NMDS and RDA supported each other's result that TOC is the most determinant variable which dominantly explained the variation in bacterial community composition across these zones. 
Table 1

\begin{tabular}{|c|c|c|c|c|c|}
\hline & & & & & \\
\hline Explanatory variable & Effect & Adjusted $\mathrm{R}^{2}$ & $\mathbf{F}$ & df & p-value \\
\hline \multirow[t]{2}{*}{$\mathrm{pH}$} & Pure & 0.006 & 1.1 & 1,11 & ns \\
\hline & Total & 0.019 & 1.3 & 1,16 & ns \\
\hline \multirow[t]{2}{*}{ EC } & Pure & -0.013 & 0.8 & 1,11 & ns \\
\hline & Total & -0.013 & 0.8 & 1,16 & ns \\
\hline \multirow[t]{2}{*}{ TOC } & Pure & 0.016 & 1.2 & 1,11 & ns \\
\hline & Total & 0.056 & 2.0 & 1,16 & 0.018 ** \\
\hline \multirow[t]{2}{*}{$P$} & Pure & 0.129 & 2.9 & 1,11 & $0.004 * * *$ \\
\hline & Total & 0.120 & 3.3 & 1,16 & $0.002^{\star * *}$ \\
\hline \multirow[t]{2}{*}{ K } & Pure & -0.002 & 1.0 & 1,11 & ns \\
\hline & Total & 0.002 & 1.0 & 1,16 & ns \\
\hline \multirow[t]{2}{*}{$\mathrm{N}$} & Pure & -0.011 & 0.8 & 1,11 & ns \\
\hline & Total & -0.004 & 0.9 & 1,16 & ns \\
\hline \multirow[t]{2}{*}{ All } & Pure & 0.188 & 1.7 & 6,11 & $0.001 * * *$ \\
\hline & Total & 0.188 & 1.7 & 6,11 & $0.001 * * *$ \\
\hline
\end{tabular}

\section{Discussion:}

Endophytes are ubiquitous in nature. Colonization of particular endophyte by plants depends on various edaphic factors. Factors such as geographic locations, soil source, host genotype and cultivation practice influence microbial communities in soil which in turn play a critical role in establishing the endospheric microbes (Edwards et al., 2015). Moreover, the composition of root exudates changes with developmental stages of plant which also affects the microbiome assembly (Imchen et al., 2019). Endophytic bacteria are generally considered as a subset of rhizospheric bacteria (Afzal et al., 2019). Therefore any changes in the rhizosphere can also alter the endophytic component. Soils rich in nutrients like organic carbon and nitrogen make the soil fertile (Sahoo et al., 2019) as well as productive and promote higher plant growth which in turn is an indication of rich rhizospheric as well as endophytic diversity in plants. Reports indicate that plants enriched with nutrients tend to have increased microbial diversity (Afzal et al., 2019). In our present study we tried to unravel the endophytic diversity in roots of rice cultivated across the different agro-ecological zones in West Bengal to understand the community change and explore the variation in bacterial community composition across the zones.

\section{Understanding the variation in environmental parameters:}

The six agro-ecological zones of West Bengal differ from each other in almost all the environmental parameters tested which are expected since the zones vary in their soil combination, landform and climate characteristics (Banerjee et al., 2019). The differences could also be attributed to different cultivation practices across the zones, as primarily it is in the farmer's hand to maintain crop yield and production (Kunda et al., 2020). In our result, the southernmost part of West Bengal represented by CSZ reported the highest EC, which is quite obvious given the fact that saline zones are characterised based on high EC (Sen \& Maji, 1994). PCA results also corroborated that separation of CSZ from the rest of the zones was mainly due to its high values of EC. The northern part of West Bengal represented by the zones - NHZ and TTAZ was seen to be rich in TOC which is in line with reports that indicated these regions have experienced low biological activity and lower decomposition of biomass. Soil organic carbon is one of the most important soil quality indicators which indicates fertility and productivity of soil (Sahoo et al., 2019). The farmers from these regions mostly cultivate high-yielding variety of rice (Kumar Bag, 2011) which justifies the fact that there is no requirement of additional fertilizers and the soil also remains untouched thus experiencing high organic carbon levels. These two zones also reported the highest available N, one of the most important nutrients for plant growth. Reports are there which indicate that soil of these regions is generally high in nitrogen content (Devi \& Sherpa, 2019) making it nutrient rich. As per PCA, VAZ experienced highest pH in soil among all the samples. The pH of VAZ was nearly neutral but in rest of the zones $\mathrm{pH}$ of soil is acidic, low $\mathrm{pH}$ could be accounted for greater rainfall in these regions that washes the basic cations rendering the soil acidic.

\section{Microbial richness across the zones:}

Alpha diversity indicates that there was significant difference in species richness among the zones. Reports are there that higher soil fertility is related to greater species diversity (Furtak et al., 2019). The high microbial species richness of rice plants in GAZ is reflected by the fact that this soil is most fertile (Banerjee et al., 2019), whereas low species richness of CSZ could be due to its high salinity, since excess salinity decreases species diversity and alters the 
community composition in plants (K. Zhang et al., 2019). The difference between GAZ and NHZ is also due to the fact that NHZ is not as fertile as GAZ and it faces difficulty in cultivation (Banerjee et al., 2019). Hence NHZ is low in endophytic microbial diversity because although the soil is nutrient dense but it is not productive, resulting in lower plant growth.

\section{Microbial community variation in the different zones:}

The members of Gammaproteobacteria, found universally in rice (Kunda et al., 2018) and abundantly in rice endorhizosphere (Moronta-Barrios et al., 2018), was seen to be dominant in case of fertilized soils (Fierer et al., 2011), intensively cultivated soil (Hamamoto et al., 2018), agricultural soil (Kuramae et al., 2012) or soil rich in N (Q. Wang et al., 2018) which is in line with our results that indicates its high abundance in GAZ, NHZ and TTAZ. These zones are characterised by soil rich in nutrients like organic carbon and nitrogen. As endophytes are a part of rhizopsheric soil therefore, we can say that enrichment of Gammaproteobacteria as root endophyte is seen in nutrient rich environment. Another class, Bacilli is also present abundantly in permanent grasslands and arable land (Mendes et al., 2013), which justifies their highest occurrence in GAZ. Bacteroidetes being abundant in nutrient rich soil (He et al., 2017) explains the high proportion of class Bacteroidia as rice root endophyte in GAZ. Abundance of Firmicutes have been seen in zones like CSZ, RLZ and TTAZ which are categorised as nutrient low groups. As reported by Mukhtar et al., 2019, this phylum is found in abundance in the rhizosphere of plants grown in extreme environments (Mukhtar et al., 2019). Firmicutes was also reported under high saline conditions (Zhang et al., 2020) and hence its representative class Clostridia is dominant in CSZ as 95\% abundance of CSZ is due to Clostridia. This class has also been reported as an abundant phyla in rice seed (Raj et al., 2019) as well as is found in rice soil (Hayat et al., 2010). Association of Alphaproteobacteria have been found to be enriched in soils having higher $\mathrm{N}$ supply (Fierer et al., 2011) as well as organic carbon (Kim et al., 2014). Alphaproteobacteria was mostly dominant in NHZ which is characterised based on both high TOC and N. Abundance of this class in NHZ can also be related to its plant growth promoting properties. As per Hardoim et al., 2011, this class occur in rice roots endophytes largely irrespective of plant genotype because their universal adaption in rice is believed to be associated with their beneficial functions which might be the driving force for their selection (Hardoim et al., 2011). It has been reported that Planctomycetes have more stable and resistant life-strategy (De León-Lorenzana et al., 2018) and hence are found in zones like RLZ, NHZ and TTAZ where soil is not perfectly suitable for cultivation. Planctomycetes is also reported to be abundant in drought condition (Dai et al., 2019) which is a characteristic of RLZ.

The most common genera found as rice root endophytes among all the sampled zones are Clostridium sensu stricto (33.7\%), Sulfurospirillum (8.3\%), Uliginosibacterium (7.7\%), Aeromonas (5.2\%), Veillonellaceae Incertae sedis (2.8\%,) Acidaminococcaceae Incertae sedis (2.4\%), Lachnospiraceae Incertae sedis (1.6\%), Bacillus (1.1\%), Burkholderiaceae Incertae sedis (1.1\%), Shewanella (1\%), Massilia (1\%), etc. These genera are already reported as rice endophytes (Hardoim et al., 2011; Kunda et al., 2018; Walitang et al., 2017) and their presence in all the sampling sites may be because they represent the core endophytic microbiomes of rice in West Bengal. Most of these genera are known diazotrophs and are reported to have plant growth promoting properties. They being present inside plants may help their host by promoting growth or tolerate stressful conditions or produce allelopathic substances to compete with other species. Genus like Massilia is reported to reduce nitrate have an important role in nitrogen cycle and thus act as a plant growth promoting bacteria (Wemheuer et al., 2017). This genus also induces production of napthoquinones like alkannin and shikowin in root cultures of a medicinal plant and thus possesses anti-microbial properties (Rat et al., 2021). Another genus, Shewanella is reported to alleviate salt stress (Paul \& Lade, 2014). Moreover, as revealed in our analysis, two zones have some specific genera that are unique to them. The unique genera for GAZ are - Dickeya, Lactococcus and Prevotellaceae Incertae sedis while for TTAZ they are - Azonexus, Pectobacterium, and Diplorickettsia.Dickeya and Lactococcus are known rice endophytes (Kunda et al., 2018; Marag \& Suman, 2018) and Prevotellaceae has no known functions in plants although it has been reported as an endophyte of fruit Pitaya (Ren et al., 2018). Among the unique genera of TTAZ, Azonexus is reported as rice endophytes (Kunda et al., 2018) but the other two genera are not reported as rice endophytes so far, Diplorickettsia is reported as an insect endosymbiont (Mathew et al., 2012) and Pectobacterium as plant pathogen (Davidsson et al., 2013). Pectobacterium possess a large number of plant cell-wall degrading enzymes (Davidsson et al., 2013) and thus may have colonised rice roots. Maybe these endophytes are signatorial bacterial genera of the particular zones whose functions are yet to be discovered.

According to dot plot, out of the 17 differentially significant OTUs many are reported as known plant growth promoting bacteria (PGPB). Genera such as Clostridium, Bacillus, Comamonas, Aeromonas, Aquitalea, Burkholderia and Enterobacter have plant growth promoting abilities by fixing nitrogen, solubilising phosphorus, potassium, zinc, producing phytohormones like IAA as well as can protect plant from pathogen attack by producing HCN and siderophore (Ishizawa et al., 2017; Mendes et al., 2013; Nath Yadav et al., 2017; Radhakrishnan et al., 2017; Saxena et al., 2020; J. Wang et al., 2020). Clodtridium apart from being a plant growth promoter (Doni et al., 2014; Emami et al., 2019) is also reported to tolerate and mitigate soil salinity (Rahman et al., 2017). Interaction of these bacteria with rice roots can contribute to the growth of the plants and can also help plants to grow under normal as well as stressful conditions.

It is worth mentioning that due to some logistical problems we were unable to complete sampling at once. We have done sampling in a span of two years in two different seasons. This could also contribute to any differences in microbial community composition. Since all the samples were not collected in the same season any direct relation of seasonal variation with endophytic composition could not be drawn.

\section{Conclusion:}

To the best of our knowledge, this is the first report on endophytic diversity of bacteria intrinsic to rice plant cultivated across the different agro-ecological zones throughout the state of West Bengal using amplicon sequencing approach. From our study, we have seen that the sampling zones could be broadly divided into two groups - nutrient dense soil group represented by GAZ, NHZ, TTAZ and nutrient low soil group represented by CSZ, RLZ and VAZ. The diversity was enriched in nutrient dense zones than in nutrient low groups. It was also found that classes like Gammaproteobacteria, Bacteroidetes and Bacilli were found in nutrient dense zones while Clostridia, Planctomycetes were abundant in nutrient low zones. The bacterial communities of different habitats differed in bacterial diversity and composition. Some endophytes like Aeromonas, Acidaminococcus, Bacillus, Clostridium, Sulfurospirillum, Uliginosibacterium are associated ubiquitously with rice across all zones. They may comprise the core microbiome of rice in West Bengal. Other genera like Prevotellaceae

Page $7 / 16$ 
Incertae sedis, Lactococcus, Dickeya, Azonexus, Diplorickettsia and Pectobacterium are unique to particular zones and are not distributed uniformly in rice. Few genera found in nutrient low zones have plant growth promoting abilities which may explain why they have been chosen by plant as an endophyte. Since, most endophytes have a bi-phasic life cycle that alternates between plant and soil environment. This diversity study has helped us to visualise the endophytic status of rice grown throughout the state of West Bengal which has provided some insight into which endophytes are inhabiting rice and what may be their probable function in that particular zone. Our future plan of work will involve culture dependent characterization of endophytes from these regions and studying their role in promoting plant growth under different conditions.

\section{Declarations:}

Funding: No such funding was available for conducting this study.

Conflict of interest: The authors declare that the research was conducted in the absence of any commercial or financial relationships that could be construed as a potential conflict of interest.

Availability of data and material: The raw sequence data reported in this paper were submitted to NCBI with Bioproject accession numbers for 16S rRNA gene sequences as following: PRJNA471586, PRJNA471587, PRJNA471590, PRJNA471599, PRJNA471617 and PRJNA394071.

Author's contribution: Conceptualization: Pranamita Kunda, Paltu Kumar Dhal and Abhishek Mukherjee; Methodology: Pranamita Kunda; Formal analysis and investigation: Pranamita Kunda and Paltu Kumar Dhal; Writing - original draft preparation: Pranamita Kunda; Writing - review and editing: Paltu Kumar Dhal and Abhishek Mukherjee; Supervision: Paltu Kumar Dhal and Abhishek Mukherjee

Ethics approval: Not applicable

Consent to participate: Not applicable

Consent for publication: Not applicable

\section{Acknowledgement:}

The authors are thankful to Indian Statistical Institute, Kolkata, for providing support to this project. We would also like to thank Jadavpur University, Life Sciences and Biotechnology Department, for providing lab space and instruments to carry out the work. We extend our sincere thanks to Mr. Sandip Mondal for helping us in sample collection. We also thank University Grants Commission for providing student fellowship.

\section{References:}

1. Afzal, I., Shinwari, Z. K., Sikandar, S., \& Shahzad, S. (2019). Plant beneficial endophytic bacteria: Mechanisms, diversity, host range and genetic determinants. In Microbiological Research (Vol. 221, pp. 36-49). Elsevier GmbH. https://doi.org/10.1016/j.micres.2019.02.001

2. Ahn, J. H., Lee, S. A., Kim, J. M., Kim, M. S., Song, J., \& Weon, H. Y. (2016). Dynamics of bacterial communities in rice field soils as affected by different long-term fertilization practices. Journal of Microbiology, 54(11), 724-731. https://doi.org/10.1007/s12275-016-6463-3

3. Arjun, J. K., \& Harikrishnan, K. (2011). Metagenomic analysis of bacterial diversity in the rice rhizosphere soil microbiome. Biotechnology Bioinf. Bioengineering, 1(3), 361-367.

4. Banerjee, S., Chandra, B., Viswavidyalaya, K., Mukherjee, A., Chandra, B., \& Viswavidyalaya, K. (2019). Contingency crop planning for different Agroclimatic zones of West Bengal Contingency crop planning for different Agro-climatic zones of West Bengal. January.

5. Banik, A., Kumar, U., ... S. M.-E. G. and, \& 2017, undefined. (2017). Dynamics of endophytic and epiphytic bacterial communities of Indian cultivated and wild rice (Oryza spp.) genotypes. Elsevier. Retrieved March 10, 2021, from https://www.sciencedirect.com/science/article/pii/S2405985417300174

6. Bardou, P., Mariette, J., Escudié, F., Djemiel, C., \& Klopp, C. (2014). Jvenn: An interactive Venn diagram viewer. BMC Bioinformatics, 15(1). https://doi.org/10.1186/1471-2105-15-293

7. Chaudhry, V., Sharma, S., Bansal, K., \& Patil, P. B. (2017). Glimpse into the genomes of rice endophytic bacteria: Diversity and distribution of firmicutes. Frontiers in Microbiology, 7(JAN), 4-8. https://doi.org/10.3389/fmicb.2016.02115

8. Checcucci, A., Azzarello, E., Bazzicalupo, M., Carlo, A. De, Emiliani, G., Mancuso, S., Spini, G., Viti, C., \& Mengoni, A. (2017). Role and regulation of ACC deaminase gene in Sinorhizobium melilotr: Is it a symbiotic, rhizospheric or endophytic gene? Frontiers in Genetics, 8(JAN).

https://doi.org/10.3389/fgene.2017.00006

9. Dai, L., Zhang, G., Yu, Z., Ding, H., Xu, Y., \& Zhang, Z. (2019). Effect of drought stress and developmental stages on microbial community structure and diversity in peanut rhizosphere soil. International Journal of Molecular Sciences, 20(9). https://doi.org/10.3390/ijms20092265

10. Davidsson, P. R., Kariola, T., Niemi, O., \& Tapio Palva, E. (2013). Pathogenicity of and plant immunity to soft rot pectobacteria. In Frontiers in Plant Science (Vol. 4, Issue JUN). Frontiers Research Foundation. https://doi.org/10.3389/fpls.2013.00191

11. De León-Lorenzana, A. S., Delgado-Balbuena, L., Domínguez-Mendoza, C. A., Navarro-Noya, Y. E., Luna-Guido, M., \& Dendooven, L. (2018). Soil salinity controls relative abundance of specific bacterial groups involved in the decomposition of maize plant residues. Frontiers in Ecology and Evolution, 6(MAY), 51. https://doi.org/10.3389/fevo.2018.00051

12. Devi, S. B., \& Sherpa, S. S. S. S. (2019). Soil carbon and nitrogen stocks along the altitudinal gradient of the Darjeeling Himalayas, India. Environmental Monitoring and Assessment, 191(6). https://doi.org/10.1007/s10661-019-7470-8 
13. Dhal, P. K., Kopprio, G. A., \& Gärdes, A. (2020). Insights on aquatic microbiome of the Indian Sundarbans mangrove areas. PLoS ONE, 15(2). https://doi.org/10.1371/journal.pone.0221543

14. Doni, F., Anizan, I., Radziah, C. M. Z. C., Ahmed, W. N. W., Ashari, A., Suryadi, E., \& Yusoff, W. M. W. (2014). Enhanced rice seedling growth by Clostridium and Pseudomonas. Biotechnology, 13(4), 186-189. https://doi.org/10.3923/biotech.2014.186.189

15. Edwards, J., Johnson, C., Santos-Medellín, C., Lurie, E., Podishetty, N. K., Bhatnagar, S., Eisen, J. A., Sundaresan, V., \& Jeffery, L. D. (2015). Structure, variation, and assembly of the root-associated microbiomes of rice. Proceedings of the National Academy of Sciences of the United States of America, 112(8), E911-E920. https://doi.org/10.1073/pnas.1414592112

16. Emami, S., Hossein, \&, Alikhani, A., Pourbabaei, A. A., Etesami, H., Sarmadian, F., \& Motessharezadeh, B. (2019). Effect of rhizospheric and endophytic bacteria with multiple plant growth promoting traits on wheat growth. https://doi.org/10.1007/s11356-019-05284-x

17. Fernandes, A. D., Reid, J. N., Macklaim, J. M., McMurrough, T. A., Edgell, D. R., \& Gloor, G. B. (2014). Unifying the analysis of high-throughput sequencing datasets: characterizing RNA-seq, 16S rRNA gene sequencing and selective growth experiments by compositional data analysis. Microbiome, 2(1), 15. https://doi.org/10.1186/2049-2618-2-15

18. Fierer, N., Lauber, C. L., Ramirez, K. S., Zaneveld, J., Bradford, M. A., \& Knight, R. (2011). Comparative metagenomic, phylogenetic and physiological analyses of soil microbial communities across nitrogen gradients. The ISME Journal, 6, 1007-1017. https://doi.org/10.1038/ismej.2011.159

19. Furtak, K., Grzadziel, J., Gałazka, A., \& Niedźwiecki, J. (2019). Analysis of soil properties, bacterial community composition, and metabolic diversity in fluvisols of a floodplain area. Sustainability (Switzerland), 11(14). https://doi.org/10.3390/su11143929

20. Ghosh, D., Sharma, D. K., \& Mattison, D. M. (2005). Goal programming formulation in nutrient management for rice production in West Bengal. International Journal of Production Economics, 95(1), 1-7. https://doi.org/10.1016/j.ijpe.2003.09.018

21. Hamamoto, T., Chirwa, M., Nyambe, I., \& Uchida, Y. (2018). Small-Scale Variability in the Soil Microbial Community Structure in a Semideveloped Farm in Zambia. https://doi.org/10.1155/2018/7939123

22. Hardoim, P. R., Dini Andreote, F., Reinhold-Hurek, B., Sessitsch, A., Simon Van Overbeek, L., \& Dirk Van Elsas, J. (2011). Rice root-associated bacteria: insights into community structures across 10 cultivars. https://doi.org/10.1111/j.1574-6941.2011.01092.x

23. Hassenrück, C., Fink, A., Lichtschlag, A., Tegetmeyer, H. E., De Beer, D., \& Ramette, A. (2016). Quantification of the effects of ocean acidification on sediment microbial communities in the environment: The importance of ecosystem approaches. FEMS Microbiology Ecology, 92(5). https://doi.org/10.1093/femsec/fiw027

24. Hayat, R., Ali, S., Amara, U., Khalid, R., \& Ahmed, I. (2010). Soil beneficial bacteria and their role in plant growth promotion: A review. In Annals of Microbiology (Vol. 60, Issue 4, pp. 579-598). BioMed Central. https://doi.org/10.1007/s13213-010-0117-1

25. He, S., Guo, L., Niu, M., Miao, F., Jiao, S., Hu, T., \& Long, M. (2017). Ecological diversity and co-occurrence patterns of bacterial community through soil profile in response to long-term switchgrass cultivation. https://doi.org/10.1038/s41598-017-03778-7

26. Imchen, M., Kumavath, R., Vaz, A. B. M., Góes-Neto, A., Barh, D., Ghosh, P., Kozyrovska, N., Podolich, O., \& Azevedo, V. (2019). 16S rRNA Gene Amplicon Based Metagenomic Signatures of Rhizobiome Community in Rice Field During Various Growth Stages. Frontiers in Microbiology, 10(September), 1-15. https://doi.org/10.3389/fmicb.2019.02103

27. Ishizawa, H., Kuroda, M., Morikawa, M., \& Ike, M. (2017). Evaluation of environmental bacterial communities as a factor affecting the growth of duckweed Lemna minor. Biotechnology for Biofuels, 10(1), 1-10. https://doi.org/10.1186/s13068-017-0746-8

28. Jackson, M L. (1967). Soil chemical analysis prentice. Hall of India Private Limited, New Delhi, 498. - Google Search. (n.d.). Retrieved March 29, 2021, from https://www.google.com/search?q=Jackson\%2C+M+L.+

(1967).+Soil+chemical+analysis+prentice.+Hall+of+India+Private+Limited\%2C+New+Delhi\%2C+498.\&rlz=1C1ASVC_enIN913IN914\&oq=Jackson\%2C+M+ (1967).+Soil+chemical+analysis+prentice.+Hall+of+India+Private+Limited\%2C+New+Delhi\%2C+498.\&aqs=chrome..69i57.892j0j15\&sourceid=chrome\&ie= 8

29. Kang, B. R., Yang, K. Y., Cho, B. H., Han, T. H., Kim, I. S., Lee, M. C., Anderson, A. J., \& Kim, Y. C. (2006). Production of indole-3-acetic acid in the plantbeneficial strain Pseudomonas chlororaphis 06 is negatively regulated by the global sensor kinase gacS. Current Microbiology, 52(6), 473-476. https://doi.org/10.1007/s00284-005-0427-x

30. Khare, E., Mishra, J., \& Arora, N. K. (2018). Multifaceted interactions between endophytes and plant: Developments and Prospects. Frontiers in Microbiology, 9(NOV), 1-12. https://doi.org/10.3389/fmicb.2018.02732

31. Kim, H. M., Jung, J. Y., Yergeau, E., Hwang, C. Y., Hinzman, L., Nam, S., Hong, S. G., Kim, O. S., Chun, J., \& Lee, Y. K. (2014). Bacterial community structure and soil properties of a subarctic tundra soil in Council, Alaska. FEMS Microbiology Ecology, 89(2), 465-475. https://doi.org/10.1111/1574-6941.12362

32. Kumar Bag, M. (2011). Status Paper on Rice in West Bengal Host-pathogen interactions between rice-Xanthomonas oryzae pv oryzae and Rice Rhizoctonia solani and Biocontrol of rice diseases. View project Management of rice diseases View project. http://www.rkmp.co.in

33. Kumar, V., AlMomin, S., Al-Aqeel, H., Al-Salameen, F., Nair, S., \& Shajan, A. (2018). Metagenomic analysis of rhizosphere microflora of oil-contaminated soil planted with barley and alfalfa. PLOS ONE, 13(8), 1-16. https://doi.org/10.1371/journal.pone.0202127

34. Kunda, P., Dhal, P. K., \& Mukherjee, A. (2018). Endophytic bacterial community of rice (Oryza sativa L.) from coastal saline zone of West Bengal: $16 S$ rRNA gene based metagenomics approach. Meta Gene, 18. https://doi.org/10.1016/j.mgene.2018.08.004

35. Kunda, Pranamita, Mukherjee, A., \& Dhal, P. K. (2020). Bacterial Biological Control Agents for Soilborne Diseases Management in Pulses: Present Status and Future Prospects. Microbial Mitigation of Stress Response of Food Legumes, 231-243. https://doi.org/10.1201/9781003028413-22

36. Kuramae, E. E., Yergeau, E., Wong, L. C., Pijl, A. S., Van Veen, J. A., \& Kowalchuk, G. A. (n.d.). Soil characteristics more strongly influence soil bacterial communities than land-use type. https://doi.org/10.1111/j.1574-6941.2011.01192.x

Page 9/16 
37. Lareen, A., Burton, F., \& Schäfer, P. (2016). Plant root-microbe communication in shaping root microbiomes. Plant Molecular Biology, 90(6), $575-587$. https://doi.org/10.1007/s11103-015-0417-8

38. Lei, S., Xu, X., Cheng, Z., Xiong, J., Ma, R., Zhang, L., Yang, X., Zhu, Y., Zhang, B., \& Tian, B. (2019). Analysis of the community composition and bacterial diversity of the rhizosphere microbiome across different plant taxa. MicrobiologyOpen, 8(6), 1-10. https://doi.org/10.1002/mbo3.762

39. Marag, P. S., \& Suman, A. (2018). Growth stage and tissue specific colonization of endophytic bacteria having plant growth promoting traits in hybrid and composite maize (Zea mays L.). Microbiological Research, 214, 101-113. https://doi.org/10.1016/j.micres.2018.05.016

40. Mashiane, R. A., Ezeokoli, O. T., Adeleke, R. A., Cornelius, ; \& Bezuidenhout, C. (2017). Metagenomic analyses of bacterial endophytes associated with the phyllosphere of a Bt maize cultivar and its isogenic parental line from South Africa Graphical Abstract Keywords 16S rRNA · Bt-maize · Bacteria · Diversity · Endophytes · Metagenomics · Plant shoots. World Journal of Microbiology and Biotechnology, 33, 3. https://doi.org/10.1007/s11274-017-2249-y

41. Mathew, M. J., Subramanian, G., Nguyen, T. T., Robert, C., Mediannikov, O., Fournier, P. E., \& Raoult, D. (2012). Genome sequence of Diplorickettsia massiliensis, an emerging ixodes ricinus-associated human pathogen. In Journal of Bacteriology (Vol. 194, Issue 12, pp. 3287-3291). J Bacteriol. https://doi.org/10.1128/JB.00448-12

42. Mendes, R., Garbeva, P., \& Raaijmakers, J. M. (2013). The rhizosphere microbiome: Significance of plant beneficial, plant pathogenic, and human pathogenic microorganisms. In FEMS Microbiology Reviews (Vol. 37, Issue 5, pp. 634-663). Oxford Academic. https://doi.org/10.1111/1574-6976.12028

43. Moronta-Barrios, F., Gionechetti, F., Pallavicini, A., Marys, E., \& Venturi, V. (2018). Bacterial Microbiota of Rice Roots: 16S-Based Taxonomic Profiling of Endophytic and Rhizospheric Diversity, Endophytes Isolation and Simplified Endophytic Community. Microorganisms, 6(1), 14. https://doi.org/10.3390/microorganisms6010014

44. Mukhtar, S., Mehnaz, S., \& Abdulla, K. (2019). Microbial diversity in the rhizosphere of plants growing under extreme environments and its impact on crop improvement. Environmental Sustainability, 0123456789. https://doi.org/10.1007/s42398-019-00061-5

45. Nath Yadav, A., Verma, P., Singh, B., Singh Chauahan, V., Suman, A., \& Kumar Saxena, A. (2017). Adv Biotech \& Micro Plant Growth Promoting Bacteria: Biodiversity and Multifunctional Attributes for Sustainable Agriculture. Review Article, 5. https://doi.org/10.19080/AlBM.2017.05.555671

46. Nautiyal, C. S., Srivastava, S., Chauhan, P. S., Seem, K., Mishra, A., \& Sopory, S. K. (2013). Plant growth-promoting bacteria Bacillus amyloliquefaciens NBRISN13 modulates gene expression profile of leaf and rhizosphere community in rice during salt stress. Plant Physiology and Biochemistry, 66, 1-9. https://doi.org/10.1016/j.plaphy.2013.01.020

47. Oksanen, J., Blanchet, F.G., Kindt, R., Legendre, P., Minchin, P.R., O’Hara, R., Simpson, G.L., Solymos, P., Stevens, M.H.H., Wagner, H. (2016). Vegan: community ecology package. R package version 1.17-8 / World Agroforestry / Transforming Lives and Landscapes with Trees. https://www.worldagroforestry.org/publication/vegan-community-ecology-package-r-package-version-117-8

48. Olanrewaju, O. S., Glick, B. R., Olubukola, ; \& Babalola, O. (2017). Mechanisms of action of plant growth promoting bacteria. World J Microbiol Biotechnol, 33, 197. https://doi.org/10.1007/s11274-017-2364-9

49. Olsen, S. R. (1954). Estimation of available phosphorus in soils by extraction with sodium bicarbonate. Undefined.

50. Paul, D., \& Lade, H. (2014). Plant-growth-promoting rhizobacteria to improve crop growth in saline soils: A review. Agronomy for Sustainable Development, 34(4), 737-752. https://doi.org/10.1007/s13593-014-0233-6

51. Pini, F., Galardini, M., Bazzicalupo, M., \& Mengoni, A. (2011). Plant-bacteria association and symbiosis: Are there common genomic traits in alphaproteobacteria? Genes, 2(4), 1017-1032. https://doi.org/10.3390/genes2041017

52. Pinski, A., Betekhtin, A., Hupert-Kocurek, K., Mur, L. A. J., \& Hasterok, R. (2019). Defining the genetic basis of plant-endophytic bacteria interactions. International Journal of Molecular Sciences, 20(8). https://doi.org/10.3390/ijms20081947

53. Radhakrishnan, R., Hashem, A., \& Abd Allah, E. F. (2017). Bacillus: A biological tool for crop improvement through bio-molecular changes in adverse environments. Frontiers in Physiology, 8(SEP), 667. https://doi.org/10.3389/fphys.2017.00667

54. Rahman, S. S., Siddique, R., \& Tabassum, N. (2017). Isolation and identification of halotolerant soil bacteria from coastal Patenga area. BMC Res Notes, 10, 531. https://doi.org/10.1186/s13104-017-2855-7

55. Raj, G., Shadab, M., Deka, S., Das, M., Baruah, J., Bharali, R., \& Talukdar, N. C. (2019). Seed interior microbiome of rice genotypes indigenous to three agroecosystems of Indo-Burma biodiversity hotspot. BMC Genomics, 2O(1), 1-16. https://doi.org/10.1186/s12864-019-6334-5

56. Rat, A., Naranjo, H. D., Krigas, N., Grigoriadou, K., Maloupa, E., Alonso, A. V., Schneider, C., Papageorgiou, V. P., Assimopoulou, A. N., Tsafantakis, N., Fokialakis, N., \& Willems, A. (2021). Endophytic Bacteria From the Roots of the Medicinal Plant Alkanna tinctoria Tausch (Boraginaceae): Exploration of Plant Growth Promoting Properties and Potential Role in the Production of Plant Secondary Metabolites. Frontiers in Microbiology, $12,113$. https://doi.org/10.3389/fmicb.2021.633488

57. Ren, Z., Tang, S., Jiang, Y., Jiang, M., Zheng, S., Liu, W., Yang, Z., Sang, S., Chen, Z., Xia, T., \& Yin, M. (2018). High-throughput sequencing analysis of endophytic bacteria diversity in fruits of white and red pitayas from three different origins. Polish Journal of Microbiology, 67(1), 27-35. https://doi.org/10.5604/01.3001.0011.6139

58. Sahoo, U. K., Singh, S. L., Gogoi, A., Kenye, A., \& Sahoo, S. S. (2019). Active and passive soil organic carbon pools as affected by different land use types in Mizoram, Northeast India. PLoS ONE, 14(7), 1-16. https://doi.org/10.1371/journal.pone.0219969

59. Saxena, A. K., Kumar, M., Chakdar, H., Anuroopa, N., \& Bagyaraj, D. J. (2020). Bacillus species in soil as a natural resource for plant health and nutrition. In Journal of Applied Microbiology (Vol. 128, Issue 6, pp. 1583-1594). Blackwell Publishing Ltd. https://doi.org/10.1111/jam.14506

60. Sen, H. S., \& Maji, B. (1994). Status of research and management of coastal saline soils for increasing crop productivity and future scope for improvement. Indian Journal of Agricultural Sciences, 64(4), 211-218. 
61. Sengupta, S., Ganguli, S., data, P. S.-G., \& 2017, undefined. (n.d.). Metagenome analysis of the root endophytic microbial community of Indian rice (O. sativa L.). Elsevier. Retrieved March 10, 2021, from https://www.sciencedirect.com/science/article/pii/S2213596017300314

62. Sessitsch, A., Hardoim, P., Döring, J., Weilharter, A., Krause, A., Woyke, T., Mitter, B., Hauberg-Lotte, L., Friedrich, F., Rahalkar, M., Hurek, T., Sarkar, A., Bodrossy, L., Van Overbeek, L., Brar, D., Van Elsas, J. D., \& Reinhold-Hurek, B. (2012). Functional Characteristics of an Endophyte Community Colonizing Rice Roots as Revealed by Metagenomic Analysis. Molecular Plant-Microbe Interactions, 25(1), 28-36. https://doi.org/10.1094/MPMI-08-11-0204

63. Taulé, C., Vaz-Jauri, P., \& Battistoni, F. (2021). Insights into the early stages of plant-endophytic bacteria interaction. World Journal of Microbiology and Biotechnology, 37(1), 1-9. https://doi.org/10.1007/s11274-020-02966-4

64. Verma, S., Ladha, J., biotechnology, A. T.-J. of, \& 2001, undefined. (n.d.). Evaluation of plant growth promoting and colonization ability of endophytic diazotrophs from deep water rice. Elsevier. Retrieved March 10, 2021, from https://www.sciencedirect.com/science/article/pii/S0168165601003339

65. Vishwakarma, P., \& Dubey, S. K. (2020). Diversity of endophytic bacterial community inhabiting in tropical aerobic rice under aerobic and flooded condition. Archives of Microbiology, 202(1), 17-29. https://doi.org/10.1007/s00203-019-01715-y

66. Walitang, D. I., Kim, K., Madhaiyan, M., Kim, Y. K., Kang, Y., \& Sa, T. (2017). Characterizing endophytic competence and plant growth promotion of bacterial endophytes inhabiting the seed endosphere of Rice. BMC Microbiology, 17(1), 1-13. https://doi.org/10.1186/s12866-017-1117-0

67. Walkley, A., \& Black, I. A. (1934). An Examination Of The Degtjareff Method For Determining Soil Organic Matter, And A Proposed Modification Of The Chromic Acid Titration Method. Soil Science, 37(1), 29-38. https://doi.org/10.1097/00010694-193401000-00003

68. Wang, J., Li, R., Zhang, H., Wei, G., \& Li, Z. (2020). Beneficial bacteria activate nutrients and promote wheat growth under conditions of reduced fertilizer application. BMC Microbiology, 20(1), 38. https://doi.org/10.1186/s12866-020-1708-z

69. Wang, Q., Wang, C., Yu, W., Turak, A., Chen, D., Huang, Y., Ao, J., Jiang, Y., \& Huang, Z. (2018). Effects of Nitrogen and Phosphorus Inputs on Soil Bacterial Abundance, Diversity, and Community Composition in Chinese Fir Plantations. Frontiers in Microbiology, 9(JUL), 1543.

https://doi.org/10.3389/fmicb.2018.01543

70. Wemheuer, F., Kaiser, K., Karlovsky, P., Daniel, R., Vidal, S., \& Wemheuer, B. (2017). Bacterial endophyte communities of three agricultural important grass species differ in their response towards management regimes. Scientific Reports, 7(1), 1-13. https://doi.org/10.1038/srep40914

71. Zhang, G., Bai, J., Tebbe, C. C., Zhao, Q., Jia, J., Wang, W., Wang, X., \& Yu, L. (2020). Salinity controls soil microbial community structure and function in coastal estuarine wetlands. Environmental Microbiology, 23, 1020-1037. https://doi.org/10.1111/1462-2920.15281

72. Zhang, K., Shi, Y., Cui, X., Yue, P., Li, K., Liu, X., Tripathi, B. M., \& Chu, H. (2019). Salinity Is a Key Determinant for Soil Microbial Communities in a Desert Ecosystem. MSystems, 4(1), 1-11. https://doi.org/10.1128/msystems.00225-18

73. Zhang, Y., Yu, X., Zhang, W., Lang, D., Zhang, X., Cui, G., \& Zhang, X. (2019). Interactions between Endophytes and Plants: Beneficial Effect of Endophytes to Ameliorate Biotic and Abiotic Stresses in Plants. Journal of Plant Biology, 62(1), 1-13. https://doi.org/10.1007/s12374-018-0274-5

\section{Figures}




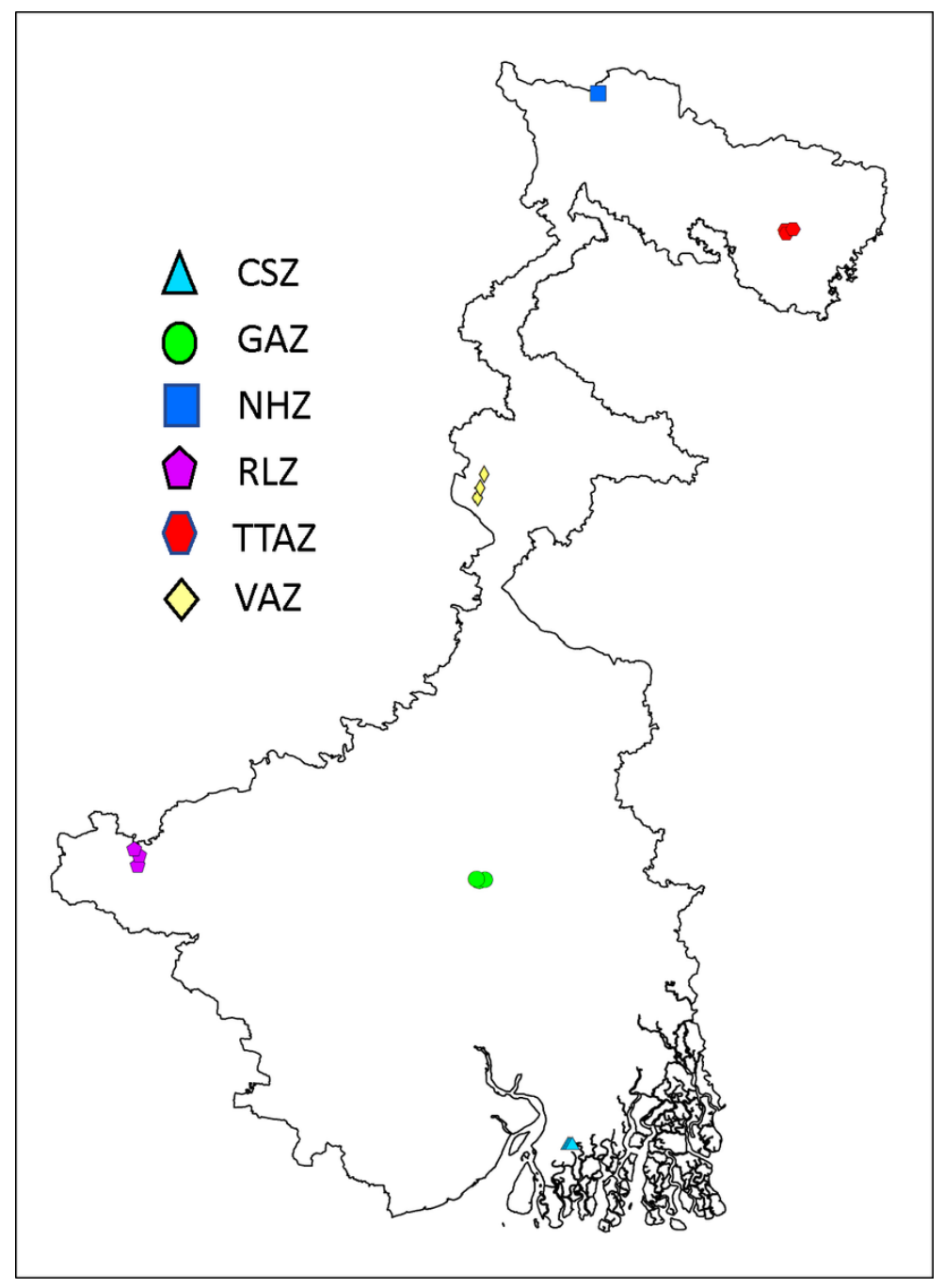

Figure 1

Map of sampling sites. Map of West Bengal showing the sampling sites with different colour codes. Each site belonged to a particular agro-ecological zone. The map was created with the help of ArcGIS 


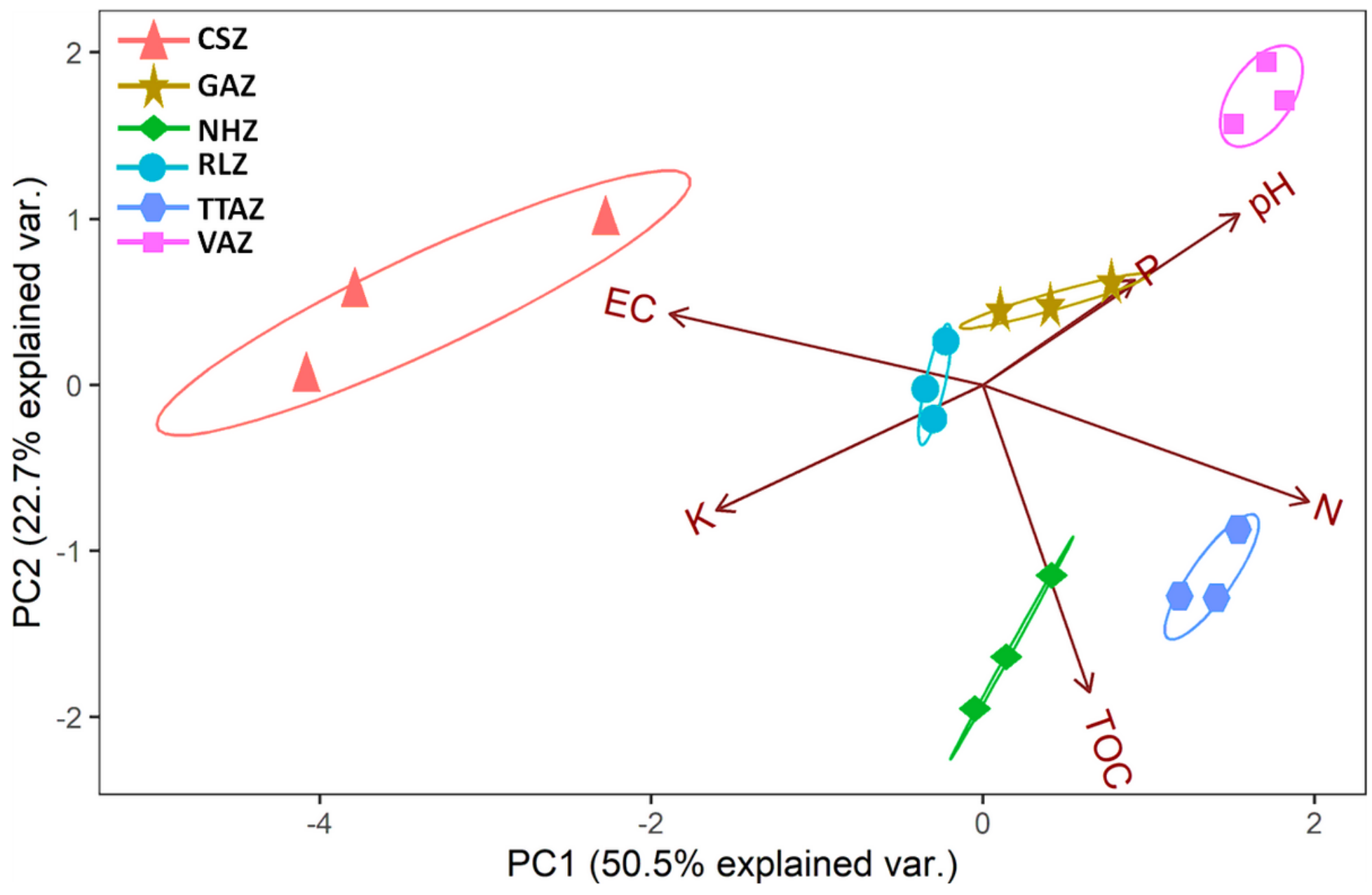

Figure 2

Principal component analysis (PCA) of environmental parameters measured at different agro-ecological zones. EC, electroconductivity; N,available Nitrogen; $\mathrm{P}$, available Phosphorus; K, exchangeable Potassium; TOC, total organic Carbon. Convex hulls were introduced to mark the three sampling sites that belonged to the same zone 


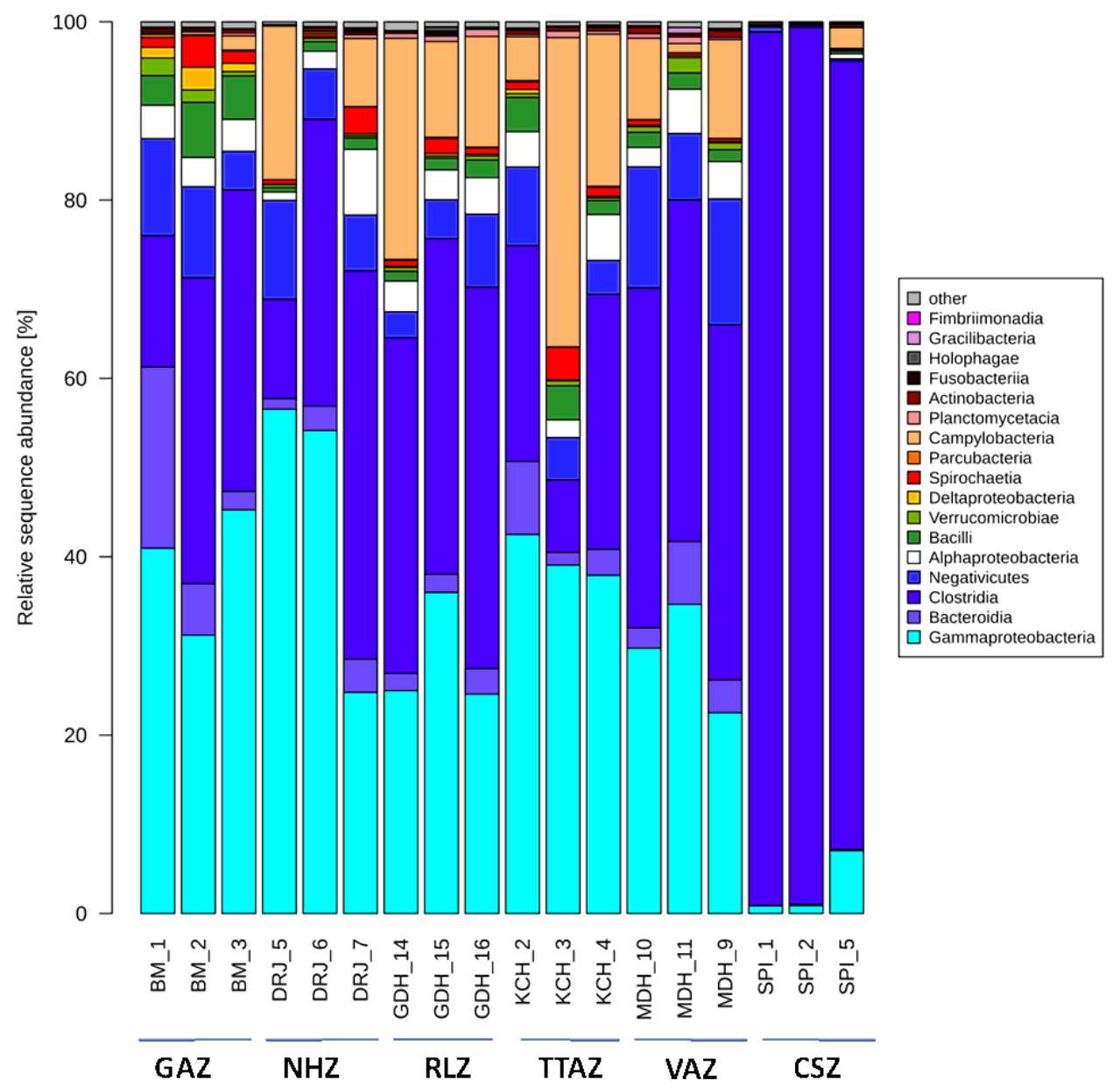

Figure 3

Taxonomic composition of the most abundant bacterial class per sample among the different agro-ecological zones. The top 10 most abundant classes per sample were chosen. For taxa that were unclassified on the respective level of resolution, the next higher level classified taxonomic rank is shown 


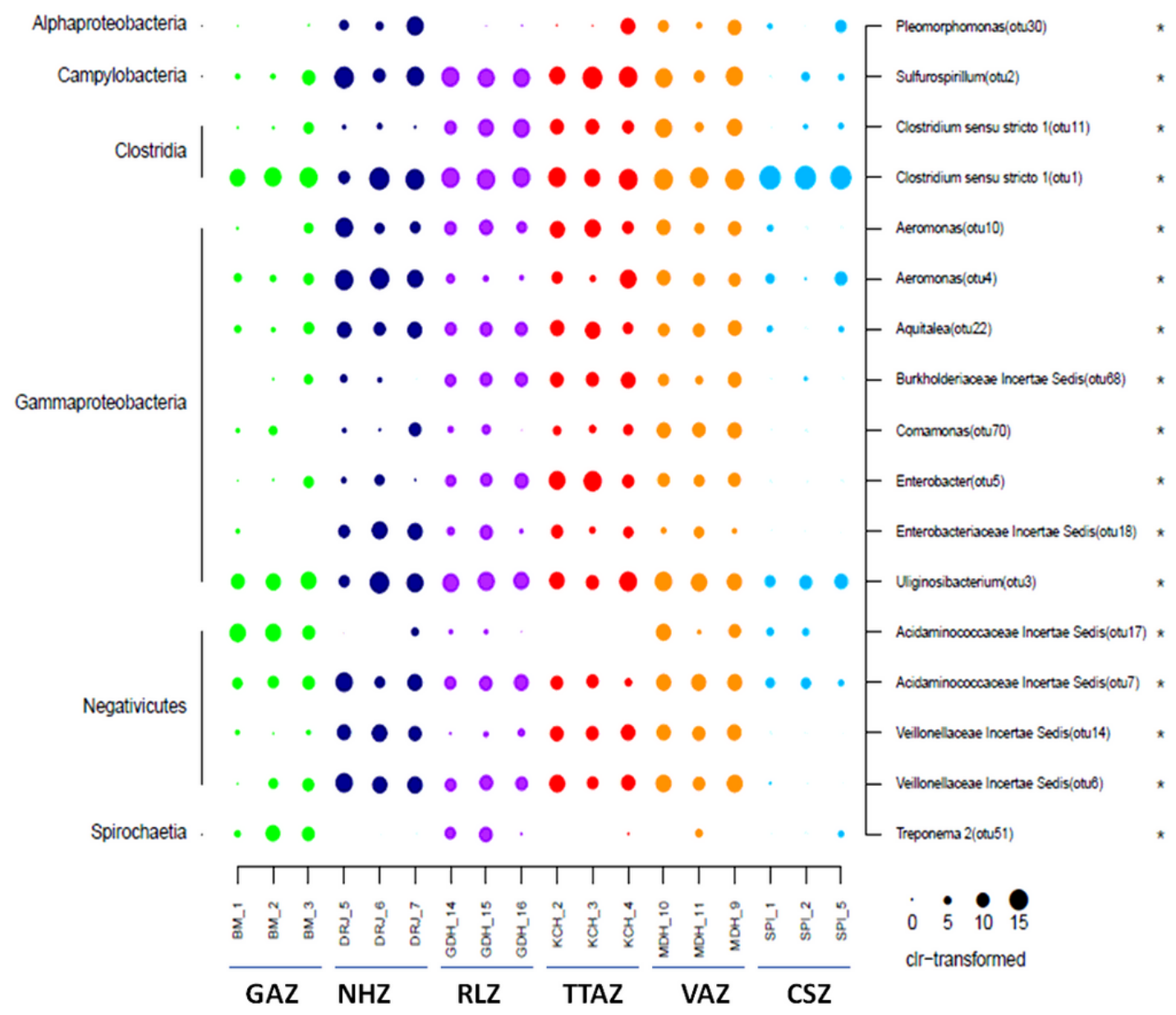

\section{Figure 4}

Dot plot of differentially abundant OTUs among the sampling sites. Site name indicates the replica number (3) at each of the six agro-ecological zones: GAZ, NHZ, RLZ, TTAZ, VAZ and CSZ. The size of each dot represents centered log ratio (clr)-transformed sequences counts. Values higher than zero indicate enrichment compared to the other OTUs per sample. The taxonomic affiliation of each OTUs is provided on class (left side) and genus level (right side). Asterisks indicate OTUs detected as differentially abundant among the sampling sites 


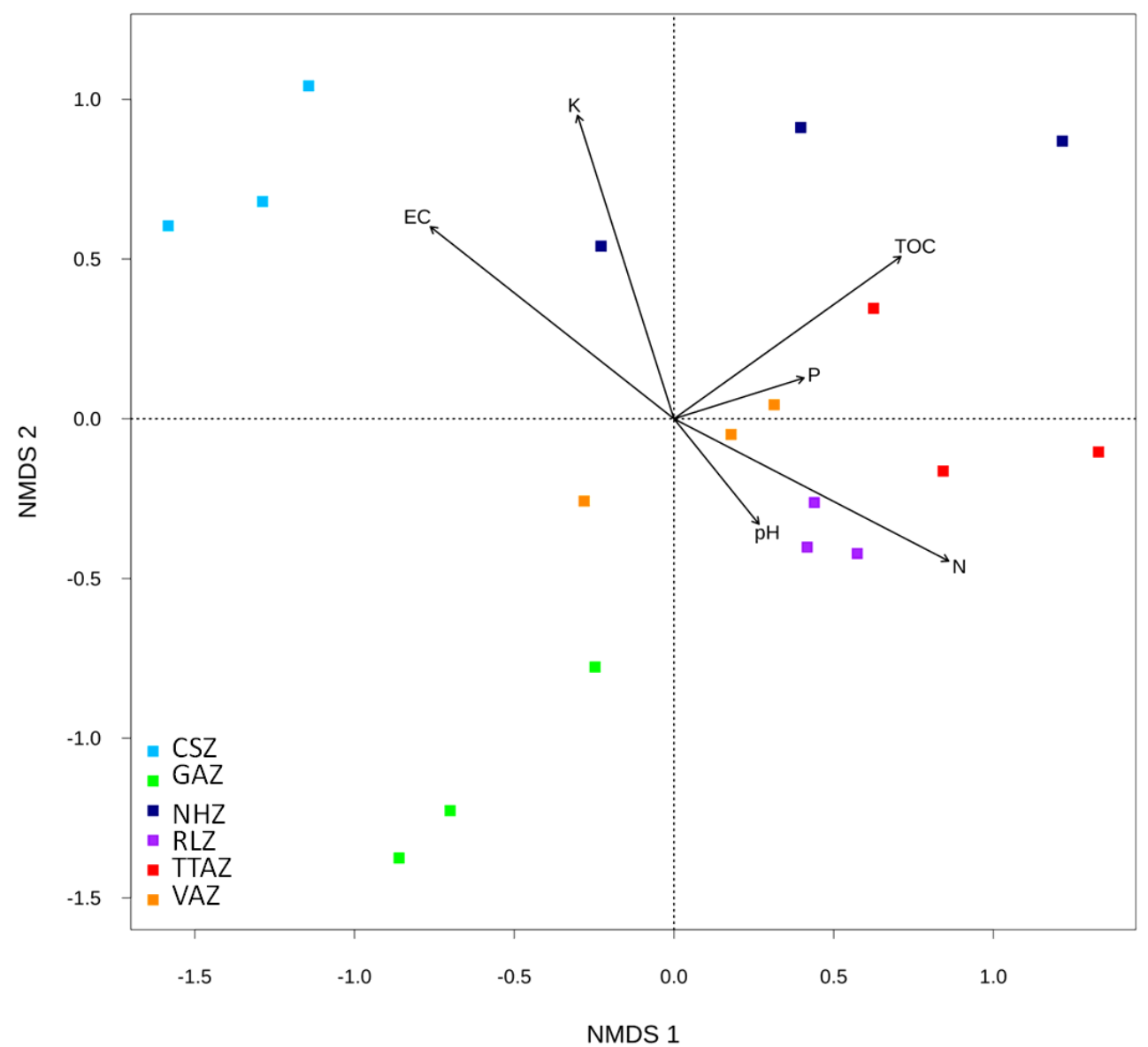

\section{Figure 5}

Non metric multidimensional scaling (NMDS) plot of the bacterial communities from the six different agro-ecological zones. Arrows indicate correlation of environmental parameters with bacterial community composition.

\section{Supplementary Files}

This is a list of supplementary files associated with this preprint. Click to download.

- Supplementaryfig1.tif

- Supplementaryfig2.tif

- Supplementaryfig3.tif

- Supplementaryfig4.tif

- Supplementaryfig5.tif

- Supplementarytable1.xlsx

- AUTHORSCHECKLIST.docx 